\title{
Can evaluation of the cervix with histogram and Bishop scoring prior to birth induction forecast the birth type for superannuated primigravidas?
}

\author{
Aytek Sık, MD, ${ }^{1}$ Murat Bozkurt, MD ${ }^{2}$ Serkan Kumbasar, MD ${ }^{2}$ Eray Çalıskan, $M D^{3}$
}

Keywords: Bishop score, cervical histogram, vaginal birth, birth induction

\begin{abstract}
Purpose: We conducted this study to research both the forecasting efficiency of the cervical histogram and Bishop scoring for birth type (vaginal birth/cesarean) for the superannuated primigravida prior to birth induction.

Methods: Ninety primigravidas in week 41 and beyond were included in the present study. Exclusions for the study included prior labor, ruptured membranes, any major uterine operations, cephalopelvic discord, fetal malpresentations, fetal anomalies, multiple pregnancy, placenta previa, vaginal bleeding, a high sensitivity for oxytocin usage, and an estimated fetal weight greater than $4000 \mathrm{~g}$. Histogram hyperechogenic focus and hypoechogenic focus measurements are conducted in normal spontaneous birth (NSD) and cesarean (SECTIO) groups.
\end{abstract}

Findings: Thirty-six patients had a cesarean birth, while 54 of the patients had vaginal births. On logarithmical regression analysis, the Bishop score and the parameters were found statistically significant in terms of proving the cesarean indication $(p=0.001)$. In our cervical histogram, the forecasting efficiency of the hyperechogenic focus and hypoechogenic focus measurements for determining the birth type were not been able to shown $(p=0.089$; $p=0.555$ ). Bishop scoring parameters showed statistically significant deviances between the NSD group compared to the cesarean group in terms of a 1-2 cm increase in cervical opening and for being 3-4 $\mathrm{cm}(p=0.0001)$, the cervical extinguishment as 40\%-50\% ( $p=0.0001)$, the occurrence of cervical softening $(p=0.0001)$, and the head level at -1 and $-2(p=0.0001)$. When declaring the cesarean indication, the Bishop score's AUC value was found as 0.932 and the $L R(+)$ value as 9; while the estimation value for the Bishop score occurring below $<5$ increased the cesarean birth risk ninefold.

Conclusion: During a superannuated nulliparous pregnancy, the Bishop score and the Bishop score's individual parameters are meaningful for vaginal birth, while a cervical histogram is not significant for forecasting the birth type.

${ }^{1}$ Department of Obstetrics and Gynecology ,Istanbul Aydin University, Istanbul, Turkey ${ }^{2}$ Department Of Obstetrics and Gynecology, Sakarya University, Sakarya, Turkey

${ }^{3}$ Department of Obstetrics and Gynecology, Bahcesehir University Medical Faculty, Istanbul, Turkey

Please cite this paper as: Şık A, Bozkurt M, Kumbasar S. Can evaluation of the cervix with histogram and Bishop scoring prior to birth induction forecast the birth type for superannuated primigravidas? Proc Obstet Gynecol. 2017;7(1): Article 5 [ 16 p.]. Available from: http://ir.uiowa.edu/pog/ Free full text article.

Corresponding author: Murat Bozkurt, Department of Obstetrics and Gynecology, Sakarya University Research and Education Hospital, Sakarya,54000, Turkey, jindrmb@yahoo.com

Financial Disclosure: The authors report no conflict of interest.

Copyright: (c) 2016 Şık et al. This is an open-access article distributed under the terms of the Creative Commons Attribution License, which permits unrestricted use, distribution, and reproduction in any medium, provided the original author and source are credited. 


\section{Introduction}

Birth induction is the iatrogenic stimulation of the uterus' contractions in order to conduct vaginal birth prior to the start of spontaneous birth action. ${ }^{1,2}$ In recent reports, birth induction usage around the world showed a significant increase and, with it, an increased morbidity risk. It was reported that $22 \%$ of births in the US, and $19.8 \%$ of births worldwide involved labor induction in 2006. 3 Elective birth inductionespecially in women with an unripe cervix-increases the cesarean birth rates regardless of the parity. ${ }^{5}$ Elective birth induction simultaneously increases postpartum bleeding, the need for blood transfusion, usage of other tonic agents, hysterectomy possibility, and labor/hospital time. 6,7 Most common birth induction cases indicate superannuation. On the birth induction applied cases, a Bishop Score is traditionally used for determining the success of the induction. In our study, the reason behind selecting the superannuated pregnancy is the practical usage of the birth induction on these patients in clinics, the high rate of cesarean birth of these patients and, because presently, there is no efficient way of determining the birth type for these patients.

\section{Material and Methods}

Our study was included 90 pregnant women who gave birth in Süleymaniye Gynecological Diseases and Maternity Education-Research Hospital. The study is a controlled prospective study.

The criteria for inclusion in this study required the patients be 41 weeks or further along in pregnancy, nulliparous, with positive fetal cardiac activity and head presentation. Exclusion parameters for the study included: patients experiencing birth activity, ruptured membranes, history of major uterine operations, cephalopelvic discrepancy, fetal malpresentations, fetal anomalies, multiple pregnancy, placenta previa, vaginal bleeding, a high sensitivity to oxytocin usage and a predicted fetal weight more than $4000 \mathrm{~g}$.

The study occurred at the Süleymaniye Gynecologic Diseases and Maternity Education-Research Hospital in the perinatology and delivery unit following the approval of the hospital training and planning committee and the committee of ethics. Between the indicated dates, patients evaluated within the scope of the study are included after completing and signing the approval form.

The gestational age of the patients was identified using their last period dates and early ultrasonography findings. Height and weight measurements of the patients are included.

The pregnant individuals included in the study group emptied their bladders prior to undergoing transvaginal ultrasonography. In transvaginal ultrasonography, a vaginal probe is inserted to the $2 \mathrm{~cm}$. proximal of the cervix without changing the shape or position of the cervix. The cervix is viewed in the sagittal plan. Histogram measurements were conducted on the sagittal plan. On this plan, an echogenic view of the cervix canal had been observed between the external and internal os. During the echogenic view of the cervix canal, the posterior and 
anterior lips of the cervix were inspected as two parts. Histogram measurements for posterior and anterior cervix lips were taken as hyperechogenic area and hypoechogenic area (Figure 1). These measurements were conducted using an ultrasonography instrument branded as General Electric Logic 9 (USA) 5 $\mathrm{MHz}$ transvaginal probe, and evaluated by the same person.

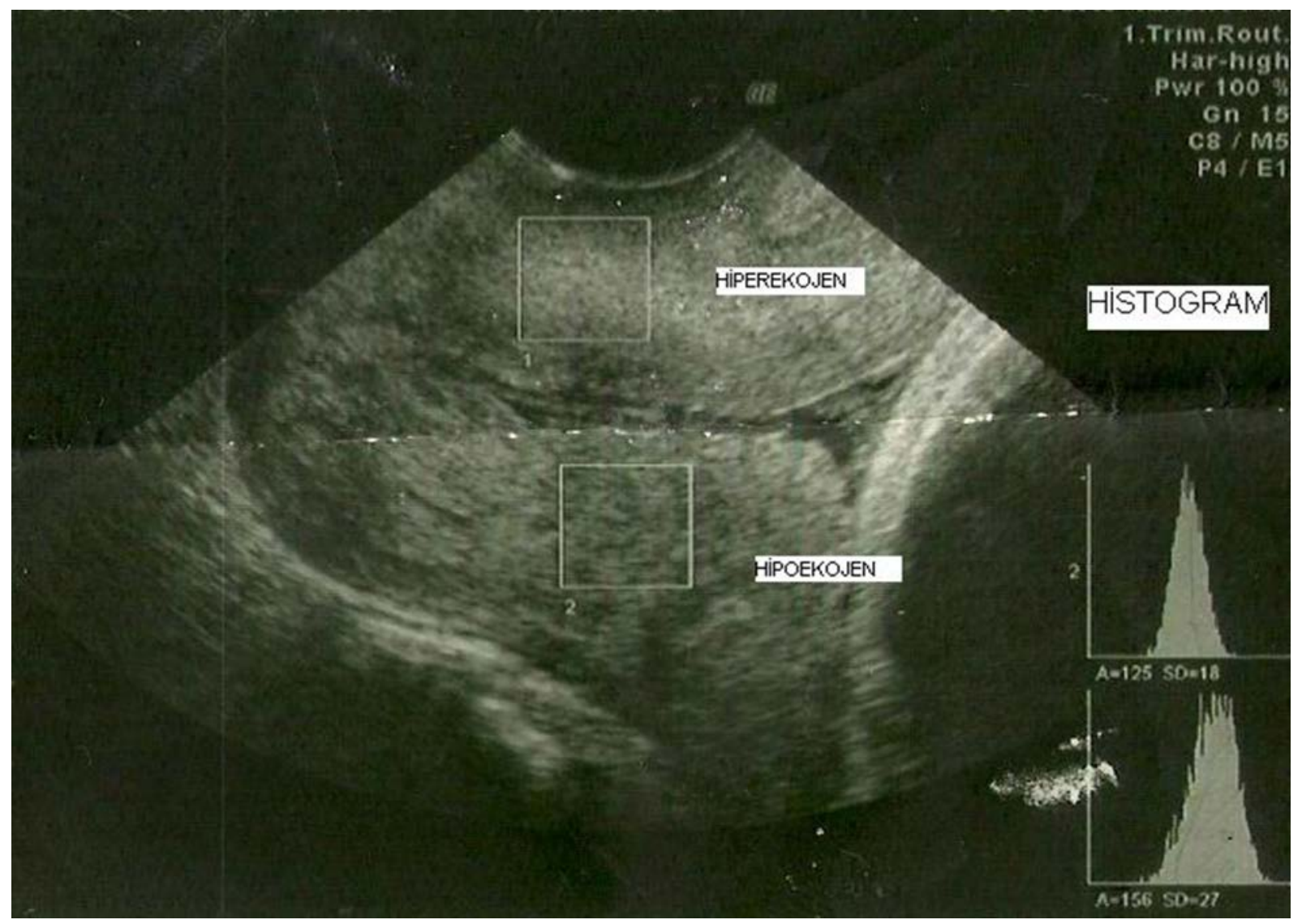

Figure 1: Description of histogram method with transvaginal ultrasonography

BPD (dual diameter), HC (head diameter), AC (belly diameter), FL (length of thigh bone), EFW (predicted baby weight), AFI (amniotic liquid index) and placenta settlement parameters are measured with transabdominal ultrasonography.

Non-stress tests were conducted on all the patients in our study group following USG by cardiotocography instrument.
Uterine contractions and fetal heart beats were inspected with the cardiotocography. A vaginal touch was conducted on the patients taken to the delivery room using the gynecologic table in lithotomy position. Bishop scoring was conducted during the vaginal touch by evaluating cervical opening, cervical extinguishment, cervical softening, level of delivered part of fetus, and Poche parameters on a 
total score of 10.

All patients were taken to a delivery room after applying clyster. "Birth Induction Method" protocol was applied to the patients in the delivery room. "Oxytocin" was used as the induction agent. The birth induction method started infusion at 10 drips per minute with $500 \%$ dextrose and 5 units of oxytocin. The infusion speed increased to 10 drips for every 20 minutes, without increasing to more than 60 drips per minute until providing the efficient contraction. The patients were continuously monitored for fetal heart beats and uterus contractions. Patients without contractions despite 12 hours of oxytocin infusion were given rest. Following their rest, patients that did not start birth action despite oxytocin infusion for another six hours were considered a failure, and were delivered via cesarean section. Inductions did not last more than 36 hours.

\section{Statistical Analysis}

The statistical analysis conducted within this study was done using SPSS (Statistical Programs for the Social Sciences Software v15 2009 USA) package software. Besides the descriptive statistical methods (mean, standard deviation) the software provided analysis for repeating measurements of the groups paired $t$ test, the comparison of the paired groups' independent $t$ test, the comparison of the qualitative data chisquare test, and the relations between variables using a Pearson correlation test. A regression analysis was used to forecast the cesarean birth logistic regression while determining the relation between the Bishop Score and other variables. ROC areas (AUC) and most probable $(\mathrm{LR}+)$ ratios were calculated for the variables describing the SECTIO indication. Results are evaluated for statistical significance level at $p<0.05$ with a trust level of $95 \%$.

\section{Table 1: Demographical specifications, Comparison of fetal measurements between groups}

\begin{tabular}{lcccc}
\hline & NSD & SECTIO & T & p \\
\hline SAT(day) & $\mathbf{2 8 8 . 1 3} \pm 2.21$ & $\mathbf{2 8 8} \pm \mathbf{1 . 4 3}$ & $\mathbf{0 . 3 1}$ & $\mathbf{0 . 7 5 6}$ \\
Abortus & $\mathbf{0 . 1 7} \pm \mathbf{0 . 5 1}$ & $\mathbf{0 . 5 8} \pm \mathbf{0 . 9 1}$ & $\mathbf{- 2 . 8 0}$ & $\mathbf{0 . 0 0 6}$ \\
Height & $\mathbf{1 6 1 . 3} \pm \mathbf{6 . 0 4}$ & $\mathbf{1 6 1 . 1 1} \pm 7.29$ & $\mathbf{0 . 1 3}$ & $\mathbf{0 . 8 9 6}$ \\
BPD & $\mathbf{9 1 . 2 3} \pm 3.5$ & $\mathbf{9 2 . 1 2} \pm \mathbf{2 . 6 6}$ & $\mathbf{- 1 . 3 0}$ & $\mathbf{0 . 1 9 7}$ \\
HC & $\mathbf{3 2 6 . 3 7} \pm \mathbf{9 . 8 6}$ & $\mathbf{3 2 7 . 7 9} \pm \mathbf{9 . 7 6}$ & $\mathbf{- 0 . 6 7}$ & $\mathbf{0 . 5 0 5}$ \\
AC & $\mathbf{3 3 8 . 1 9} \pm \mathbf{1 2 . 4}$ & $\mathbf{3 3 9 . 0 1} \pm \mathbf{1 5 . 6 3}$ & $\mathbf{- 0 . 2 8}$ & $\mathbf{0 . 7 8 4}$ \\
FL & $\mathbf{7 1 . 8 8} \pm 2.76$ & $\mathbf{7 2 . 4 1} \pm \mathbf{1 . 9 2}$ & $\mathbf{- 1 . 0 1}$ & $\mathbf{0 . 3 1 6}$ \\
EFW & $\mathbf{3 2 6 2 . 4 6} \pm \mathbf{2 9 3 . 9 5}$ & $\mathbf{3 3 0 8 . 1 4} \pm 308.4$ & $\mathbf{- 0 . 7 1}$ & $\mathbf{0 . 4 8 1}$ \\
AFI & $\mathbf{9 1 . 1 9} \pm \mathbf{2 8 . 5 4}$ & $\mathbf{9 4 . 9 7} \pm 36.37$ & $\mathbf{- 0 . 5 5}$ & $\mathbf{0 . 5 8 2}$ \\
\hline
\end{tabular}

NSD: Vaginal birth; SECTIO: Cesarean birth; SAT: Last menstruation date 


\section{Findings}

Thirty-six cases included in our study had cesarean birth, while 54 of the cases had vaginal birth. We named the cases with vaginal birth as NSD group and cases with cesarean birth as SECTIO group. Demographical parameters, height, abortus, and last menstruation dates are compared between groups. The results are shown in Table-1.

There were no statistically significant differences between NSD and SECTIO groups in terms of SAT, abortus, height, Bi-parietal diameter (BPD), Head circumference $(H C)$, Abdominal Circumference (AC), Femur length (FL), Amniotic Fluid Index (AFI) averages.

Histogram hyperechogenic focus and hyperechogenic focus measurements and individual hyperechogenic focus measurements are compared between groups. (Table 2). There was no statistically significant difference between NSD and SECTIO groups in terms of Histogram A averages $(p=0.089)$ and Histogram B averages $(p=0.555)$. Histogram $A$ averages were found greater compared to Histogram B averages as statistically significant $(p=0.0001)$. This indicates that histogram measurements are not significant for forecasting the birth type. During the histogram, hyperechogenic focus measurements were found to be greater compared to hypoechogenic focus measurements. If we only use histogram measurements for forecasting the birth type, hyperechogenic focus is more significant compared to hypoechogenic focus. Individually, hyperechogenic focus measurement is not statistically significant for forecasting the birth type $(p=0.169)$.

Histogram A's AUC value found as 0.588 and LR (+) value found as 1.27. Histogram B's AUC value found as 0.515 and LR (+) value found as 1.14. (Table 3).

Table 2. Comparison of histogram measurements and individual hyperechogenic focus measurements between groups

\begin{tabular}{lcccc}
\hline & NSD & SECTIO & $t$ & $p$ \\
\hline Histogram A & $165.24 \pm 23.3$ & $173.05 \pm 17.32$ & -1.71 & 0.089 \\
Histogram B & $119.27 \pm 21.8$ & $122 \pm 20.7$ & -0.59 & 0.555 \\
T & 14.8 & 12.38 & & \\
P & 0.0001 & 0.0001 & & \\
Histogram & $142.26 \pm 19.47$ & $147.53 \pm 14.51$ & -1.39 & 0.169 \\
Hyperechogenic & & & & \\
\hline
\end{tabular}

NSD: Vaginal birth; SECTIO: Cesarean birth; A: hyperechogenic focus; B: hypoechogenic focus 


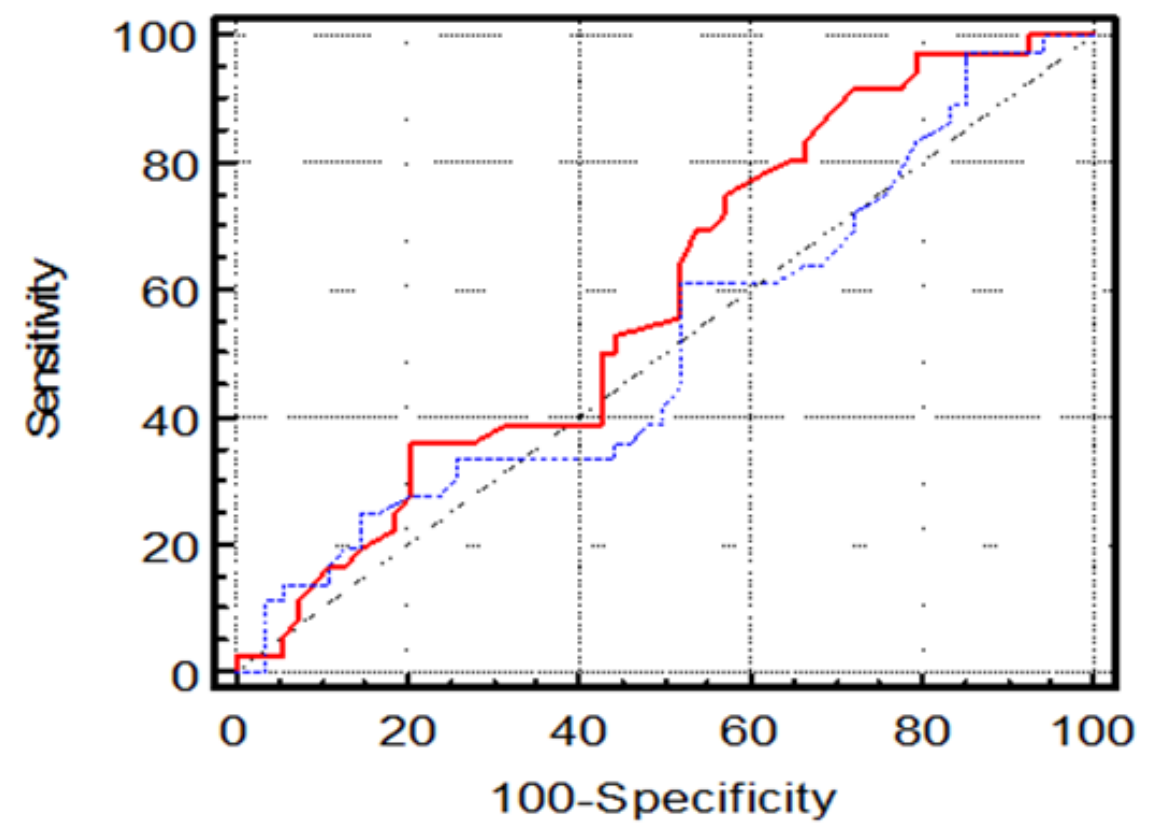

Hyperechogen Histogram

Hypoechogen Histogram

Graph 1. ROC curve for hyperechogenic and hypoechogenic focus on histogram for describing cesarean indication

\section{Table 3. Histogram values regarding SECTIO indication}

\begin{tabular}{l|cccc|} 
& Estimation Point & LR+ & AUC \pm SE & $95 \%$ GA \\
\hline Histogram A & $>150$ & 1.27 & $0.588 \pm 0.062$ & $0.479-0.691$ \\
Histogram B & $>95$ & 1.14 & $0.515 \pm 0.063$ & $0.407-0.622$ \\
\hline
\end{tabular}

A: Hyperechogenic focus; B: Hyperechogenic focus

We have compared Bishop score averages between the groups (Table 4).

Bishop score averages of SECTIO group were found to be greater compared to NSD group as statistically significant. $(p=0.0001)$.
Bishop score parameters are evaluated separately as cervical opening, cervical extinguishment, cervical softening, and level of head. The distribution of these parameters is compared between groups (Table 5). NSD and SECTIO groups with a cervical opening of 1-2 cm 
and 3-4 cm, a cervical extinguishment of $40 \%-50 \%$, an occurrence of cervical softening, and a head level at -1 and -2 were found to be statistically significant in terms of forecasting the vaginal birth.

Table 4. Comparison of Bishop score average between groups

\begin{tabular}{|lcccc|}
\hline & NSD & SECTIO & $\mathbf{t}$ & $\mathbf{p}$ \\
\hline Bishop Score & $6.17 \pm 1.43$ & $2.39 \pm 1.82$ & 10.9 & 0.0001 \\
\hline
\end{tabular}

NSD: Vaginal Birth; SECTIO: Cesarean Birth

As per the acquired $p$ values, it seemed that the Bishop score and the individual parameters of the Bishop score are statistically meaningful for vaginal birth.
Statistically significant results were found between Bishop score and cardiotocography (CTG) contraction frequency by conducting Linear Regression analysis $(p=0.03)$. (Table 6$)$.

Table 5. Distribution and comparison of the cases as per bishop score criteria

\begin{tabular}{|c|c|c|c|c|c|c|}
\hline & & \multicolumn{2}{|c|}{ NSD } & \multicolumn{2}{|c|}{ SECTIOO } & \\
\hline \multirow[t]{3}{*}{ Cervical opening } & Closed & 5 & $9.3 \%$ & 16 & $44.4 \%$ & \\
\hline & $1-2 \mathrm{~cm}$ & 38 & $70.4 \%$ & 19 & $52.8 \%$ & $\chi^{2}: 17.5$ \\
\hline & $3-4 \mathrm{~cm}$ & 11 & $20.4 \%$ & 1 & $2.8 \%$ & $p=0.0001$ \\
\hline \multirow[t]{2}{*}{ Cervical extinguishment } & $\% 0-30$ & 34 & $63.0 \%$ & 36 & $100.0 \%$ & $\chi^{2}: 17.14$ \\
\hline & $\% 40-50$ & 20 & $37.0 \%$ & 0 & $0.0 \%$ & $p=0.0001$ \\
\hline \multirow[t]{3}{*}{ Cervical softening } & Hard & 1 & $1.9 \%$ & 17 & $47.2 \%$ & \\
\hline & Medium & 2 & $3.7 \%$ & 6 & $16.7 \%$ & $\chi^{2}: 36.65$ \\
\hline & Soft & 51 & $94.4 \%$ & 13 & $36.1 \%$ & $p=0.0001$ \\
\hline \multirow[t]{3}{*}{ Level of head } & -3 & 7 & $13.0 \%$ & 26 & $72.2 \%$ & \\
\hline & -2 & 21 & $38.9 \%$ & 7 & $19.4 \%$ & $\chi^{2}: 37.40$ \\
\hline & -1 & 26 & $48.1 \%$ & 3 & $8.4 \%$ & $p=0.0001$ \\
\hline
\end{tabular}

NSD: Vaginal Birth; SECTIO: Cesarean Birth

Table 6. Linear Regression analysis between Bishop score and CTG contraction frequency

Bishop Score

\begin{tabular}{|l|c|c|c|c|c|}
\hline \multicolumn{1}{|c|}{$\mathbf{R}$} & $\mathbf{R}^{2}$ & Adjusted $\mathbf{R}^{2}$ & $\mathbf{R}^{2}$ Change & $\begin{array}{c}\mathbf{F} \\
\text { Change }\end{array}$ & $\mathbf{P}$ \\
\hline \multirow{2}{*}{0.229} & 0.153 & 0.121 & 0.153 & 4.89 & $\mathbf{0 . 0 3}$ \\
\hline & Unstandardized Coefficients & Standardized Coefficients & $\mathbf{t}$ & $\mathbf{p}$ \\
\cline { 2 - 6 } & $\mathbf{B}$ & $\mathbf{S E}$ & $\mathbf{B e t a}$ & 1.11 & 0.268 \\
\hline (Constant) & 1.577 & 1.41 & & 2.21 & $\mathbf{0 . 0 3}$ \\
\hline CTG Cont. Frequency & 0.716 & 0.324 & 0.229 & & \\
\hline
\end{tabular}


Table 7. Comparison between histogram findings and other findings

Histogram A

\begin{tabular}{|c|c|c|c|}
\hline AGE & $\mathbf{r}$ & 0.036 & 0.133 \\
\hline \multirow[b]{2}{*}{ BMI } & $\mathbf{p}$ & 0.734 & 0.21 \\
\hline & $\mathbf{r}$ & 0.064 & 0.029 \\
\hline \multirow[b]{2}{*}{ Bishop Score } & $\mathbf{p}$ & 0.546 & 0.788 \\
\hline & $\mathbf{r}$ & -0.139 & 0.069 \\
\hline \multirow[b]{2}{*}{ BPD } & $\mathbf{p}$ & 0.191 & 0.518 \\
\hline & $\mathbf{r}$ & 0.076 & 0.068 \\
\hline \multirow[b]{2}{*}{ HC } & $\mathbf{p}$ & 0.477 & 0.526 \\
\hline & $\mathbf{r}$ & 0.094 & 0.027 \\
\hline \multirow{3}{*}{ AC } & $\mathbf{p}$ & 0.378 & 0.804 \\
\hline & $\mathbf{r}$ & -0.11 & -0.04 \\
\hline & $\mathbf{p}$ & 0.302 & 0.709 \\
\hline \multirow[t]{2}{*}{ FL } & $\mathbf{r}$ & 0.177 & 0.166 \\
\hline & $\mathbf{p}$ & 0.094 & 0.117 \\
\hline \multirow[t]{2}{*}{ EFW } & $\mathbf{r}$ & -0.019 & 0.028 \\
\hline & $\mathbf{p}$ & 0.855 & 0.796 \\
\hline AFI & $\mathbf{r}$ & -0.09 & -0.15 \\
\hline \multirow{3}{*}{ CTG Cont. Freq. } & $\mathbf{p}$ & 0.397 & 0.158 \\
\hline & $\mathbf{r}$ & -0.063 & -0.119 \\
\hline & $\mathbf{p}$ & 0.556 & 0.264 \\
\hline Latent Phase Duration & $\mathbf{r}$ & 0.054 & -0.029 \\
\hline \multirow{3}{*}{ Active Phase Duration } & $\mathbf{p}$ & 0.611 & 0.788 \\
\hline & $\mathbf{r}$ & 0.158 & 0.157 \\
\hline & $\mathbf{p}$ & 0.167 & 0.169 \\
\hline
\end{tabular}

A: Hyperechogenic focus; B: Hyperechogenic focus

Histogram measurement parameters obtained with transvaginal ultrasonography for the cases are compared with other parameters in our study (Table 7).

Histogram and Bishop scoring prior to birth induction
Histogram B

ROC curves generated between the factors affecting the cesarean birth (Graph 2).

The Bishop score's AUC value was 
found as 0.932 and LR (+) value as 9 . These values, in terms of describing the cesarean indication for a Bishop Score $<5$, increases the cesarean birth risk ninefold.

The latent phase duration's (as hours) AUC value was found as 0.642 and LR (+) value as 4.87 . These values, in terms of describing the cesarean indication, latent phase duration (hours) as $>19$ hours, increases the cesarean birth risk 4.87 times.

CTG contraction frequency's AUC was found as 0.682 and LR (+) value as 5.5. These values, in terms of describing the cesarean indication CTG contraction frequency as <4, increases the cesarean birth risk 5.5 times.
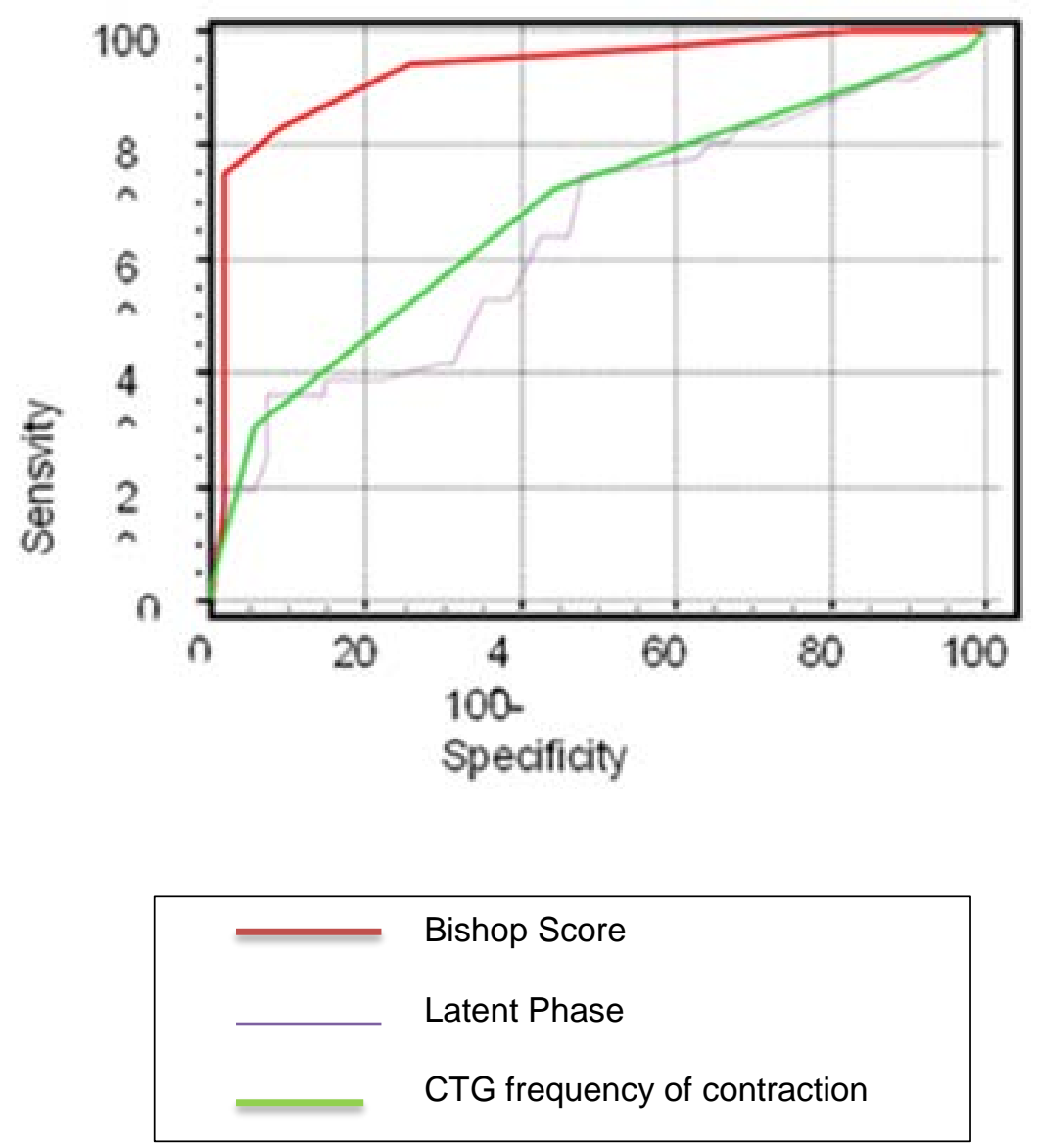

Graph 2. ROC curves between the factors affecting cesarean birth 
Table 8. Bishop score, latent phase, CTG contraction frequency in terms of describing cesarean indication

\begin{tabular}{lcccc}
\hline & Estimation Point & LR + & AUC \pm SE & $95 \%$ GA \\
\hline Bishop Score & $<5$ & 9 & $0.932 \pm 0.026$ & $0.859-0.974$ \\
Latent Phase & $>19$ hours & 4.87 & $0.642 \pm 0.061$ & $0.534-0.740$ \\
CTG Cont. Freq. & $<4$ & 5.5 & $0.682 \pm 0.056$ & $0.576-0.777$ \\
\hline
\end{tabular}

\section{Discussion}

In the US, $14 \%$ of the pregnancies passed 41 weeks and 6\% passed 42 weeks, in 2005. Extended pregnancies calculated using the first day of the last menstruation that continue more than 42 weeks (294 days) are risky for both the fetus and mother. ${ }^{8}$

Postterm pregnancy is a pregnancy that extends to 42 weeks of gestation or beyond. Fetal, neonatal and maternal complications associated with this condition have always been underestimated. It is not well understood why some women become postterm although obesity, hormonal and genetic factors have been implicated. The management of postterm pregnancy constitutes a challenge to clinicians; knowing who to induce, who will respond to induction and who will require a cesarean section (CS). The current definition and management of postterm pregnancy have been challenged in several studies as the emerging evidence demonstrates that the incidence of complications associated with postterm pregnancy also increase prior to 42 weeks of gestation. It seems therefore that a policy of induction of labor at 41 weeks in postterm women could be beneficial with potential improvement in perinatal outcome and a reduction in maternal complications. $^{9}$

In studies comparing birth induction and spontaneous birth, it was shown that the possibility of cesarean with induction is more for women with unripe cervixes. $^{10,11}$ Bishop scoring seems to be the most cost efficient, easy to apply, accurate and appropriate method for identifying the status of the cervix. ${ }^{12}$ Also, a simplified type of this scoring with dilatation, effacement and level components is reported to have the same result as the original one. ${ }^{13}$ Many countries are applying induction for pregnancies over 41 weeks. ${ }^{14}$ In the SOGC Clinical Guidelines, the authors suggested that the women should be offered induction at $41+0$ to $42+0$ weeks, as the present evidence reveals a decrease in perinatal mortality without increased risk of Cesarean section. ${ }^{15}$

A vaginal delivery with oxytocin varied between $78.5 \%$ and $85 \%$ in various studies. $^{16,17}$ In the conducted metaanalysis, the average cesarean birth rate for birth induction with oxytocin was found as $21.5 \%$.

In a study from our country, to compare the obstetric outcome of induction of labor at 41 weeks and of follow-up until 42 weeks and induction if the patient has still not given birth at 42 weeks. The treatments used in the induction group 
were (1) vaginal administration of 50 microg misoprostol ( $n=100)$, (2) oxytocin induction ( $n=100)$, and (3) transcervical insertion of a Foley balloon $(n=100)$. The primary outcome measures were the cesarean delivery rate, whether or not the normal hospital stay had to be extended, and the neonatal outcomes. Secondary outcome measure included number of emergency cesarean deliveries performed for abnormalities of the fetal heart rate (FHR). The abdominal delivery rate was $19.3 \%$ in the induction group and $22 \%$ in the follow-up group $(p=0.4)$. The mean length of hospital stay in the two main groups was $1.4+/-0.8$ days and $1.3+/-1$ days, respectively $(p=0.1)$. Significantly higher rates of macrosomia and shoulder dystocia were seen in the follow-up group (24.6 and $2.3 \%$ ) than in the induction group $(7.6 \%, p<0.001$; $0.3 \%, \quad p=0.03)$. Meconium-stained amniotic fluid and meconium aspiration syndrome were observed significantly less frequently in the induction group (9.3 and 1.3\%) than in the follow-up group (20.3\%, $\mathrm{p}<0.001 ; 4 \%, \mathrm{p}=0.03$ ). Rates of emergency abdominal delivery in response to worrying FHR traces, neonatal intensive care unit admission, and low umbilical artery $\mathrm{pH}$ were similar in the two groups. There was one intrauterine fetal death in the follow-up group. The authors conclude that, Induction of labor at 41 weeks of gestation does not increase the cesarean delivery rate or cause a longer stay in hospital than follow-up until 42 weeks, and neonatal morbidity is also lower after induction ${ }^{18}$

In our study, oxytocin was used as an induction for birth activity. For birth induction with oxytocin, the vaginal birth rate was found as $60 \%(n=54)$, while the cesarean birth rate was found as 40 $(n=36)$. Cesarean births were due to preeclampsia, 27\%, non-response to induction, $5.5 \%$, fetal distress, $50 \%$, and non-progressing delivery indications, $41.8 \%$. NSD and cesarean groups are compared in terms of demographical specifications, last menstruation date, abortus, and height. No statistically significant differences were found.

In our study, no statistically significant differences were found between NSD and SECTIO groups in terms of BPD, $\mathrm{HC}, \mathrm{AC}, \mathrm{FL}, \mathrm{EFW}, \mathrm{AFI}$ averages.

In their studies regarding cases diagnosed with premature birth risk, Hellmeyer et al. compared the histogram, cervical length, and Bishop score. They compared histogram and cervical length values to each other and, as histogram parameters decreased, cervical length values also decreased. When determining the premature birth risk, histogram and cervical length values were found to be statistically significant individually, but no differences were observed with their combinations. The group also compared the Bishop score with the cervical length and found it to be statistically significant. No correlation was observed for the comparison of the Bishop score and histogram parameters. Parameters belonging to the histogram, cervical length, and Bishop score are inspected with logistic regression analysis and the most valuable parameter found was in the histogram. In our study, we used two histogram measurements as hyperechogenic focus and hypoechogenic focus. We compared these parameters for vaginal birth and 
cesarean birth groups. We found that histogram parameters are not statistically significant in terms of forecasting the birth type. In our study, we consider hyperechogenic focus to be more significant for forecasting the birth type compared to hypoechogenic focus measurement, as hyperechogenic focus measurement is greater. We also compared histogram parameters, Bishop score, latent phase and active phase durations. We could not find any significant relation between histogram parameters and other parameters in terms of forecasting the birth type.

Patients are followed by cardiotocography (CTG) frequently. In our study, vaginal birth possibility increases with the CTG contraction frequency.

In our study, the latent phase duration for the patients giving birth by cesarean was found to be higher compared to the patients giving birth vaginally, and was statistically significant.

For the 36 patients with cesarean birth, $33 \%(n=12)$ were not able to enter the active phase, while $66.7 \%(n=24)$ were able to enter to active phase.

If birth induction is existent with inappropriate cervical status, it is also coexistent with increased section risk. ${ }^{19,20}$ A Bishop score is one of the commonly used methods for evaluating cervical ripening; however, the score's success for determining the birth induction is limited. ${ }^{21,22}$

Models were developed with the methods for forecasting the results of the birth induction. In another study, it was reported that, by digital evaluation of the cervical dilatation's combination cervical length, fetal head-perineum distance and posterior cervical opening's ultrasonographic evaluation, birth induction success can be better forecasted. ${ }^{23}$ It was found that for the models where cervical length, parity, body mass index, maternal and gestational age are combined, or maternal height, body mass index, parity, and cervical length combined are not found to be sufficient for forecasting the induction success. ${ }^{24,25,26}$ Also introduced recently was a new scoring system where parity, sonographic cervix length and posterior cervical length are evaluated together. Sensitivity of this scoring system for forecasting vaginal birth is $95.5 \%$, specificity is $84.6 \%$, the Bishop scoring sensitivity for $>5$ is $65.3 \%$, and the specificity is $80.6 \%$ as reported. $^{27}$

In a previously conducted metaanalysis, it was reported that cervix length can forecast a successful birth induction. However, with the result parameters evaluated individually (vaginal birth, vaginal within 24 hours of commencement of induction, duration of reaching to active phase) it was found that the diagnostic validity and significance were nullified and it was not forecasting vaginal or cesarean birth. The presence of cervical funneling is reported to forecast a successful induction. When compared with the Bishop score, the diagnostic validity of transvaginal sonography and cervix length were not found to be superior. ${ }^{28}$ Peak value for an unripe cervix Bishop score is $<6$, and for ultrasonography and cervix length is $>30 \mathrm{~mm}$. When considered with funneling, transvaginal 
sonography length measurement was found to decrease the prostaglandin necessity compared to the Bishop score. ${ }^{29,30}$ In the study conducted by Ramon et al. ${ }^{31}$ cervical length was not found to be a better indicator for determining the birth type compared to the Bishop score.

Gonen et al. $^{32}$ found a significant correlation between the Bishop score and parity for determining birth type and birth duration; however, the group did not find any significant relation for cervical length. In our study, we studied Bishop score parameters for vaginal birth and cesarean birth. For forecasting the birth type to be found significant, the cervical opening had to be more than 2 $\mathrm{cm}$, the cervical extinguishment had to be $30 \%$ or more, and the forthcoming part of the fetus to be -2 or more. When comparing these parameters, the cervical opening and cervical extinguishment was found to be more significant than other parameters.

In a study conducted by Crane et al.while indicating multi-parity, induction degree, cervical opening, cervical effacement, cervical position and pregnancy age as independent forecasters for a successful vaginal birth in the conducted logistic regression analysis-the Bishop score was determined a non-complying forecasting power. ${ }^{33}$ A study conducted by Mark et al. showed the cervical opening prior to induction to have a better forecasting power compared to the Bishop Score and its parameters. ${ }^{34}$

In our study, we generated ROC curves and a logistic regression analysis for the Bishop score, latent phase, and CTG contraction frequency values in regards to presenting cesarean indication. The Bishop score's AUC value found as 0.932 and LR (+) value as 9. These values, in terms of describing the cesarean indication for a Bishop score $<5$, increases the cesarean birth risk ninefold. The latent phase duration's (as hours) AUC value found as 0.642 and LR (+) value as 4.87 . These values, in terms of describing the cesarean indication for a latent phase duration (hours) $>19$ hours, increases the cesarean birth risk 4.87 times. The CTG contraction frequency's AUC was found as 0.682 and LR (+) value as 5.5. These values, in terms of describing the cesarean indication for a CTG contraction frequency $<4$, increases the cesarean birth risk 5.5 times.

\section{Conclusion}

During a superannuated nulliparous pregnancy, the Bishop score and the Bishop score's individual parameters are significant for vaginal birth, while a cervical histogram is non-significant for forecasting the birth type following birth induction.

\section{References}

1. ACOG Committee on Practice Bulletins -- Obstetrics. ACOG Practice Bulletin No. 107: Induction of labor. Obstet Gynecol. 2009 Aug;114(2 Pt 1):386-97. http://dx.doi.org/10.1097/AOG.0b013e3 181b48ef5 PubMed PMID: 19623003.

2. Ashton DM. Elective delivery at less than 39 weeks. Curr Opin Obstet Gynecol. 2010 Dec;22(6):506-10. http://dx.doi.org/10.1097/GCO.0b013e3 283404eb4 PubMed PMID: 20978440. 
3. NICE guideline. Induction of labour. National Collaborating Centre for Women's and Children's Health. National Institute for Health and Clinical Excellence 2008; www.nice.org.uk/nicemedia/live/1201 2/41255.pdf

4. Martin JA, Hamilton BE, Sutton PD, et al. Births: final data for 2006. Natl Vital Stat Rep 2009; 57: 1 - 102.

5. Guerra GV, Cecatti JG, Souza JP, Faúndes A, Morais SS, Gülmezoglu AM, Passini R Jr, Parpinelli MA, Carroli G; WHO Global Survey on Maternal Perinatal Health in Latin America Study Group. Elective induction versus spontaneous labour in Latin America. Bull World Health Organ. 2011 Sep 1;89(9):657-65.

http://dx.doi.org/10.2471/BLT.08.061226 Epub 2011 Jul 5. PubMed PMID: 21897486.

6. Vardo JH, Thornburg LL, Glantz JC. Maternal and neonatal morbidity among nulliparous women undergoing elective induction of labor. J Reprod Med. 2011 Jan-Feb;56(1-2):25-30. PubMed PMID: 21366123.

7. Cammu H, Martens G, Ruyssinck G, Amy JJ. Outcome after elective labor induction in nulliparous women: a matched cohort study. Am J Obstet Gynecol. $2002 \quad$ Feb;186(2):240-4. http://dx.doi.org/10.1067/mob.2002.119 643 PubMed PMID: 11854642.

8. Martin JA, Hamilton BE, Sutton PD, Ventura SJ, Menacker F, Kirmeyer S, Munson ML; Centers for Disease Control and Prevention National Center for Health Statistics National Vital Statistics System. Births: final data for 2005. Natl Vital Stat Rep. 2007 Dec 5;56(6):1-103. PubMed PMID: 18277471.
9. Galal M, Symonds I, Murray H, Petraglia F, Smith R. Postterm pregnancy. Facts Views Vis Obgyn. 2012;4(3):175-87. PubMed PMID: 24753906.

10. Yeast JD, Jones A, Poskin M. Induction of labor and the relationship to cesarean delivery: A review of 7001 consecutive inductions. Am J Obstet Gynecol. 1999 Mar;180(3 Pt 1):628-33. http://dx.doi.org/10.1016/S00029378(99)70265-6 PubMed PMID: 10076139.

11. Vahratian A, Zhang J, Troendle JF, Sciscione AC, Hoffman MK. Labor progression and risk of cesarean delivery in electively induced nulliparas. Obstet Gynecol. 2005 Apr;105(4):698704.

http://dx.doi.org/10.1097/01.AOG.00001 57436.68847.3b PubMed PMID: 15802393

12. Laughon SK, Zhang J, Troendle J, Sun L, Reddy UM. Using a simplified Bishop score to predict vaginal delivery. Obstet Gynecol. 2011 Apr;117(4):805-11. http://dx.doi.org/10.1097/AOG.0b013e3 182114ad2 PubMed PMID: 21383643.

13. Ponkey SE, Cohen AP, Heffner LJ, Lieberman E. Persistent fetal occiput posterior position: obstetric outcomes. Obstet Gynecol. 2003 May;101(5 Pt 1):915-20.

http://dx.doi.org/10.1097/00006250200305000-00016 PubMed PMID: 12738150 .

14. Rayburn WF. Clinical experience with a controlled-release, prostaglandin E2 intravaginal insert in the USA. $\mathrm{Br} \mathrm{J}$ Obstet Gynaecol. 1997 Oct;104 Suppl 15:8-12; discussion 20-5. PubMed PMID: 9366721. 
15. Clinical Practice Obstetrics Committee.; Maternal Fetal Medicine Committee., Delaney M, Roggensack A, Leduc DC, Ballermann $C$, Biringer $A$, Delaney $M$, Dontigny L, Gleason TP, Shek-Yn Lee $\mathrm{L}$, Martel MJ, Morin V, Polsky JN, Rowntree C, Shepherd DJ, Wilson K. Guidelines for the management of pregnancy at $41+0$ to $42+0$ weeks. J Obstet Gynaecol Can. 2008 Sep;30(9):800-23. English, French. http://dx.doi.org/10.1016/S17012163(16)32945-0 PubMed PMID: 18845050.

16. Sanchez-Ramos L, Kaunitz AM, Del Valle GO, Delke I, Schroeder PA, Briones DK. Labor induction with the prostaglandin E1 methyl analogue misoprostol versus oxytocin: a randomized trial. Obstet Gynecol. 1993 Mar;81(3):332-6. PubMed PMID: 8437780 .

17. Escudero F, Contreras H. A comparative trial of labor induction with misoprostol versus oxytocin. Int J Gynaecol Obstet. 1997 May;57(2):13943. http://dx.doi.org/10.1016/S00207292(97)02873-7 PubMed PMID: 9184950 .

18. Gelisen O, Caliskan E, Dilbaz S, Ozdas E, Dilbaz B, Ozdas E, Haberal A. Induction of labor with three different techniques at 41 weeks of gestation or spontaneous follow-up until 42 weeks in women with definitely unfavorable cervical scores. Eur J Obstet Gynecol Reprod Biol. 2005 Jun 1;120(2):164-9. https://doi.org/10.1016/j.ejogrb.2004.08. 013 PubMed PMID: 15925045.

19. Sheibani I, Wing DA. Abnormal labor and induction of labor. Techniques for Cervical Ripening and Labor Induction. Chapter 13. In: Gabbe SG, Niebyl JR, Simpson JL, Galan HL, Landon MB, Jauniaux ERM, Driscoll DA, Berghella V, Grobman WA, editors. Obstetrics: Normal and Problem Pregnancies. 7th ed. Philadelphia: Elsevier; 2017.
20. Seyb ST, Berka RJ, Socol ML, Dooley SL. Risk of cesarean delivery with elective induction of labor at term in nulliparous women. Obstet Gynecol. 1999 Oct;94(4):600-7. http://dx.doi.org/10.1097/00006250199910000-00022 PubMed PMID: 10511367.

21. Leppert PC. Anatomy and physiology of cervical ripening. Clin Obstet Gynecol. 1995 Jun;38(2):267-79. http://dx.doi.org/10.1097/00003081199506000-00009 PubMed PMID: 7554594 .

22. Chazan B, Niemiec KT, Filipp E. [Postterm pregnancy--importance of this problem in modern obstetrics]. Ginekol Pol. 1996 Mar;67(3):148-56. Polish. PubMed PMID: 8647509.

23. Eggebø TM, Økland I, Heien C, Gjessing LK, Romundstad P, Salvesen KA. Can ultrasound measurements replace digitally assessed elements of the Bishop score? Acta Obstet Gynecol Scand. 2009;88(3):325-31. http://dx.doi.org/10.1080/000163409027 30417 PubMed PMID: 19172418.

24. Peregrine E, O'Brien $\mathrm{P}$, Omar $\mathrm{R}$, Jauniaux E. Clinical and ultrasound parameters to predict the risk of cesarean delivery after induction of labor. Obstet Gynecol. 2006 Feb;107(2 $\mathrm{Pt}$

1):227-33. http://dx.doi.org/10.1097/01.AOG.00001 96508.11431.c0 PubMed PMID: 16449105.

25. Rane SM, Guirgis RR, Higgins $B$, Nicolaides $\mathrm{KH}$. Models for the prediction of successful induction of labor based on pre-induction sonographic measurement of cervical length. J Matern Fetal Neonatal Med. 2005 May;17(5):315-22. http://dx.doi.org/10.1080/147670505001 27690 PubMed PMID: 16147844. 
26. Verhoeven $\mathrm{CJ}$, Oudenaarden $\mathrm{A}$, Hermus MA, Porath MM, Oei SG, Mol BW. Validation of models that predict Cesarean section after induction of labor. Ultrasound Obstet Gynecol. 2009 Sep;34(3):316-21.

http://dx.doi.org/10.1002/uog.7315

PubMed PMID: 19670397.

27. Keepanasseril A, Suri $V$, Bagga $R$, Aggarwal N. A new objective scoring system for the prediction of successful induction of labour. J Obstet Gynaecol. 2012 Feb;32(2):145-7. http://dx.doi.org/10.3109/01443615.201 1.637142 PubMed PMID: 22296424.

28. Hatfield AS, Sanchez-Ramos L, Kaunitz AM. Sonographic cervical assessment to predict the success of labor induction: a systematic review with metaanalysis. Am J Obstet Gynecol. 2007 Aug;197(2):186-92. http://dx.doi.org/10.1016/j.ajog.2007.04. 050 PubMed PMID: 17689645.

29. Bartha JL, Romero-Carmona R, Martínez-Del-Fresno P, CominoDelgado R. Bishop score and transvaginal ultrasound for preinduction cervical assessment: a randomized clinical trial. Ultrasound Obstet Gynecol. 2005 Feb;25(2):155-9. http://dx.doi.org/10.1002/uog.1813 PubMed PMID: 15660437.

30. Park KH, Kim SN, Lee SY, Jeong EH, Jung $\mathrm{HJ}$, Oh KJ. Comparison between sonographic cervical length and Bishop score in preinduction cervical assessment: a randomized trial. Ultrasound Obstet Gynecol. 2011 Aug;38(2):198-204. http://dx.doi.org/10.1002/uog.9020

PubMed PMID: 21484904.
31. Roman H, Verspyck E, Vercoustre L, Degre S, Col JY, Firmin JM, Caron P, Marpeau L. Does ultrasound examination when the cervix is unfavorable improve the prediction of failed labor induction? Ultrasound Obstet Gynecol. 2004 Apr;23(4):357-62. http://dx.doi.org/10.1002/uog.1008 PubMed PMID: 15065185.

32. Gonen R, Degani S, Ron A. Prediction of successful induction of labor: comparison of transvaginal ultrasonography and the Bishop score. Eur J Ultrasound. 1998 Aug;7(3):183-7. http://dx.doi.org/10.1016/S09298266(98)00042-1 PubMed PMID: 9700213.

33. Crane JM, Delaney T, Butt KD, Bennett KA, Hutchens D, Young DC. Predictors of successful labor induction with oral or vaginal misoprostol. J Matern Fetal Neonatal Med. 2004 May;15(5):319-23. http://dx.doi.org/10.1080/147670504100 01702195 PubMed PMID: 15280123.

34. Williams MC, Krammer J, O'Brien WF. The value of the cervical score in predicting successful outcome of labor induction. Obstet Gynecol. 1997 Nov;90(5):784-9. http://dx.doi.org/10.1016/S00297844(97)00415-8 PubMed PMID: 9351765 . 